\title{
Evaluation of Fatigue, Sleep Quality and Activities of Daily Living in Patients with Chronic Renal Failure
}

\author{
Sema ÖZBERK ${ }^{1}$ iD and Deniz KOCAMAZ*² \\ ${ }^{1}$ Dokuz Eylül University, Health Sciences Institute, İzmir, TURKEY \\ ${ }^{2}$ Hasan Kalyoncu University, Faculty of Health Sciences, Department of Physiotherapy and Rehabilitation, Gaziantep, \\ TURKEY \\ *Corresponding author: denizerdan@gmail.com
}

\begin{abstract}
Introduction: Patients receiving hemodialysis treatment for chronic renal failure (CRF) develop various symptoms and experience lifestyle changes. CRF is a progressive disease characterized by irreversible loss of nephrons. Objective: The aim of the study was to evaluate fatigue, sleep quality and activities of daily living in patients with chronic renal failure. Method: This was a descriptive cross-sectional study. Sixty-seven CRF patients aged over 18 years who admitted to a private dialysis center for hemodialysis treatment were included. Sociodemographic information was recorded and the 'Visual Analog Scale for Fatigue' was used to evaluate fatigue, the 'Pittsburgh Sleep Quality Index' for assessment of sleep quality and the 'Katz Activities of Daily Living Scale' for evaluation of activities of daily living for all patients. All evaluations were conducted by the same investigator before hemodialysis session. Fatigue level assessment was repeated after hemodialysis session. The data obtained were analyzed using the SPSS 24.0 software package. Results: Thirty (44.8\%) females and 37 (55.2\%) males were enrolled in the study. The mean age of the study population was $55.8 \pm 15.75$ years. $74.6 \%$ of the patients had poor sleep quality. The mean fatigue score of the patients was $4.82 \pm 2.02$ before hemodialysis and $8.79 \pm 1.67$ after hemodialysis, as assessed by Visual Analog Scale for Fatigue. All participants were independent in activities of daily living. The average of Katz Activities of Daily Living Scale was $17.03 \pm 0.57$. Conclusion: In line with former studies, fatigue was the most common symptom in the study patients undergoing hemodialysis treatment for chronic renal failure. Additionally, poor sleep quality and reduced performance in the activities of daily living in the study participants are noteworthy. Hemodialysis causes a number of symptoms that patients have to cope with in their daily lives. It is important to guide patients about individualized rehabilitation programs in the treatment of chronic renal failure.
\end{abstract}

Keywords

Fatigue; Hemodialysis; Sleep quality; Activities of daily living; Rehabilitation

\section{INTRODUCTION}

Chronic renal failure (CRF) is a public health concern which not only affects the medical condition but also social, economic and psychological state of the patients. Thus, it is of utmost importance to slow the disease progression and treat complications (Noel and Rieu, 2012; Tiğlı and Yakut, 2020).

Chronic renal failure is defined as a reduced glomerular filtration rate or the presence of proteinuria. Diabetic nephropathy and hypertensive kidney damage account for the majority of cases. Before initiation of treatment, it should be considered whether causal treatment of the underlying disease is possible and indicated. While specific treatment is not possible in all patients, therapy should aim at reducing progression of renal failure. CRF tend to be associated with intrinsic deterioration that persists after cessation of the causative damaging pathological mechanism. Renal failure progression 
can be delayed and the most important measures include strict blood pressure control, reduction of proteinuria and preventing further renal injury (Girndt, 2017). CRF patients may have important loss of daily life activities (DLA) during hemodialysis. Sarcopenia with consequent muscle weakness, immobilization on upper extremity and Local factors, such as the arteriovenous (A-V) may cause that falling of DLA (Fonseca et al., 2020).

In Turkey, hemodialysis therapy is administered in two or three sessions per week at a dialysis unit, depending on the prognosis of the disease. Each treatment session usually lasts for three to four hours. Throughout the session, patients are maintained in the supine or recumbent position. Fatigue is one of the most common debilitating symptoms that occur as a side effect of long-term dialysis treatment and physical inactivity during this process (Tuna et al., 2018). Fatigue has a substantial effect on patients' health-related quality of life. Daytime sleepiness resulting from poor sleep quality also contributes to fatigue. Moreover, activities of daily living are also affected in patients undergoing hemodialysis, which is associated with impaired quality of life. Possible interventions to minimize fatigue in patients receiving long-term dialysis treatment should aim at improving awareness among healthcare providers, developing improved methods of measurements, better understanding of the pathogenesis and management of established contributing factors (Jhamb et al., 2008).

Further studies are warranted to demonstrate the impact of side effects of hemodialysis treatment and individual's skills to cope with the disease on the activities of daily living. The present study was designed to evaluate fatigue, sleep quality and activities of daily living in CRF patients undergoing hemodialysis treatment.

\section{METHODS}

This was a descriptive cross-sectional study. The study data were collected from November 2018 to December 2019. Sixty-seven CRF patients who admitted to a private dialysis center in the city of Gaziantep for hemodialysis treatment and met inclusion criteria were included in the study. Fully oriented, conscious patients aged over 18 years without communication difficulties who received hemodialysis treatment at least twice weekly for 6 months or longer were eligible for the study. Patients were excluded from the study if they (1) were prior neurological, rheumatologically and orthopedic upper limb problems (2) patients who have had surgery of upper limbs, (3) with diabetes mellitus and (4) patients doing hemodialysis through catheter were also excluded.

For collecting the study data, a patient identification form addressing the sociodemographic characteristics of patients developed by the study investigators based on relevant literature was used. Assessments for the study were conducted using the Visual Analog Scale for Fatigue (VAS-F) for fatigue, the Pittsburgh Sleep Quality Index (PSQI) for sleep quality and the Katz Activities of Daily Living Scale (Katz-ADL) for activities of daily living. All assessments were performed by the same investigator prior to hemodialysis session. Fatigue level assessment was repeated after hemodialysis session.

\section{Visual Analog Scale for Fatigue (VAS-F)}

This scale was developed by Lee et al. and consists of 18 items. A Turkish version of the VAS-F is used for assessment of fatigue in hemodialysis patients and its reliability and validity were demonstrated by Yurtsever and colleagues. The scale is a $10-\mathrm{cm}$ line and possible score ranges from 0 to 10 . The items $1,2,3,4,5$, $11,12,13,14,15,16,17$ and 18 are related to the fatigue subscale and items $6,7,8,9$ and 10 are related to the energy subscale. The most positive response is scored 0 point and the most negative response is scored 10 points in the fatigue subscale, whereas the most negative response is scored 0 point and the most positive response is scored 10 points in the energy subscale (Lee et al., 1991; Yurtsever and Bedük, 2003).

\section{Pittsburgh Sleep Quality Index (PSQI)}

The PSQI consists of a total of 24 questions and 7 components and reliability and validity of a Turkish version of the scale was demonstrated by Ağargün et al. The PSQI is a self-rated questionnaire that is used for screening and assessment purposes. It provides detailed information on sleep quality and type and severity of sleep disturbance over a 1-month time interval. Scoring is based on 19 items and 7 components. Each item is assigned a score between 0 and 3 and the global PSQI score is calculated by totaling the 
7 component scores. An overall score ranges from 0 to 21 and a higher total score indicates worse sleep quality. A total PSQI score of 5 or greater denotes "bad sleep" and a score less than 5 indicates "good sleep" (Ağargün et al., 1996).

\section{Katz Activities of Daily Living Scale}

The Katz-ADL scale consists of six questions that address bathing, dressing, toileting, transferring, continence and feeding activities. Individuals are scored yes/no for independence in each of the six functions. A score of 3 means the person is independent, a score 2 indicates that the person requires assistance and a score of 1 denotes that the person cannot perform ADLs at all. Based on the scale scores, patients scored 0-6 points were considered as "dependent", patients scored 7-12 points as "semi-dependent" and patients scored 13-18 points as "independent" (Aydın et al., 2009; Tel H et al., 2006).
The data obtained were analyzed using the SPSS 24.0 software package. Results were summarized as means and standard deviations. Descriptive statistics were presented as means and percentages. The Kolmogorov-Smirnov test was used to check the normality of data distribution. Sociodemographic and clinical characteristics of the groups were compared using the Student's t-test. Correlations among variables were assessed using Spearman analyses. The significance level was set at $\mathrm{p}<0.05$ for all analyses.

\section{RESULTS}

The study sample had a mean age of $55.8 \pm 15.75$ years and consisted of $30(44.8 \%)$ females and $37 \quad(55.2 \%)$ males. Sociodemographic and clinical characteristics of the patients are shown in Table 1.

Table 1. Sociodemographic and Clinical Characteristics of the Patients by Gender

\begin{tabular}{|c|c|c|c|c|}
\hline & $\begin{array}{c}\text { Female } \\
(n=30)\end{array}$ & $\begin{array}{c}\text { Male } \\
(\mathrm{n}=37)\end{array}$ & $\begin{array}{c}\text { Total } \\
(n=67)\end{array}$ & $\mathbf{p}$ \\
\hline $\begin{array}{c}\text { Age, years }(\mathrm{X} \pm \mathrm{SD}) \\
\text { min-max }\end{array}$ & $\begin{array}{c}49.93 \pm 18.22 \\
18-75\end{array}$ & $\begin{array}{c}55.13 \pm 13.22 \\
19-74\end{array}$ & $\begin{array}{c}55.8 \pm 15.75 \\
18-75\end{array}$ & 0.181 \\
\hline $\begin{array}{l}\text { Time from initiation of HD treatment, } \\
\text { months }(X \pm S D) \\
\quad \text { min-max }\end{array}$ & $\begin{array}{c}40.04 \pm 43.07 \\
6-192\end{array}$ & $\begin{array}{l}53.64 \pm 47.22 \\
7-192\end{array}$ & $\begin{array}{c}47.55 \pm 45.58 \\
6-192\end{array}$ & 0.227 \\
\hline $\begin{array}{l}\text { Hemodialysis frequency, } \mathrm{n}(\%) \\
2 \text { sessions per week } \\
3 \text { sessions per week }\end{array}$ & $\begin{array}{c}5(16) \\
25(84)\end{array}$ & $\begin{array}{c}3(1) \\
34(99)\end{array}$ & $\begin{array}{c}8(12) \\
59(88)\end{array}$ & 0.034 \\
\hline $\begin{array}{l}\text { VAS-F score, before HD }(\mathrm{X} \pm \mathrm{SD}) \\
\text { min-max }\end{array}$ & $\begin{array}{c}5.36 \pm 1.82 \\
1-8\end{array}$ & $\begin{array}{c}4.37 \pm 2.09 \\
1-8\end{array}$ & $\begin{array}{c}4.82 \pm 2.02 \\
1-8\end{array}$ & 0.047 \\
\hline $\begin{array}{l}\text { VAS-F score, after HD }(\mathrm{X} \pm \mathrm{SD} \\
\text { min-max }\end{array}$ & $\begin{array}{l}8.73 \pm 1.83 \\
1-10\end{array}$ & $\begin{array}{l}8.83 \pm 1.55 \\
2-10\end{array}$ & $\begin{array}{c}8.79 \pm 1.67 \\
1-10\end{array}$ & 0.802 \\
\hline $\begin{array}{l}\text { PSQI score }(\mathrm{X} \pm \mathrm{SD}) \\
\text { min-max }\end{array}$ & $\begin{array}{l}9.70 \pm 4.54 \\
0-15\end{array}$ & $\begin{array}{c}8.05 \pm 4.89 \\
0-16\end{array}$ & $\begin{array}{c}8.79 \pm 4.77 \\
0-16\end{array}$ & 0.163 \\
\hline $\begin{array}{l}\text { ADL score }(\mathrm{X} \pm \mathrm{SD}) \\
\text { min-max } \\
\text { (Independent }(\mathbf{1 3 - 1 8} \text { points })\end{array}$ & $\begin{array}{c}17.27 \pm 0.45 \\
17-18\end{array}$ & $\begin{array}{c}16.45 \pm 0,60 \\
16-18\end{array}$ & $\begin{array}{c}17.03 \pm 0.57 \\
16-18\end{array}$ & 0.437 \\
\hline
\end{tabular}

HD: Hemodialysis, VAS-F: Visual Analog Scale for Fatigue, PSQI: Pittsburgh Sleep Quality Index, ADL: Katz Activities of Daily Living Scale

Increased level of fatigue was observed in patients after hemodialysis treatment and $74.6 \%$ of the patients had poor sleep quality. However, no difference was found in activities of daily living and independence level among patients in relation to CRF.
The mean VAS-F score of the patients was $4.82 \pm 2.02$ before hemodialysis and $8.79 \pm 1.67$ after hemodialysis. All patients were independently functioning during activities of daily living with a mean Katz-ADL score of $17.03 \pm 0.57$ (Table 1). 
Fatigue level was greater in females before treatment, while it was greater in males after treatment, as assessed by VAS-F. Female patients had worse sleep quality than male patients. KatzADL scores were lower among male patients.
Table 2 shows data on the relations among fatigue, sleep quality and activities of daily living before hemodialysis session in patients undergoing hemodialysis treatment 2 to 3 times weekly.

Table 2. Relations Among Fatigue, Sleep Quality and Activities of Daily Living

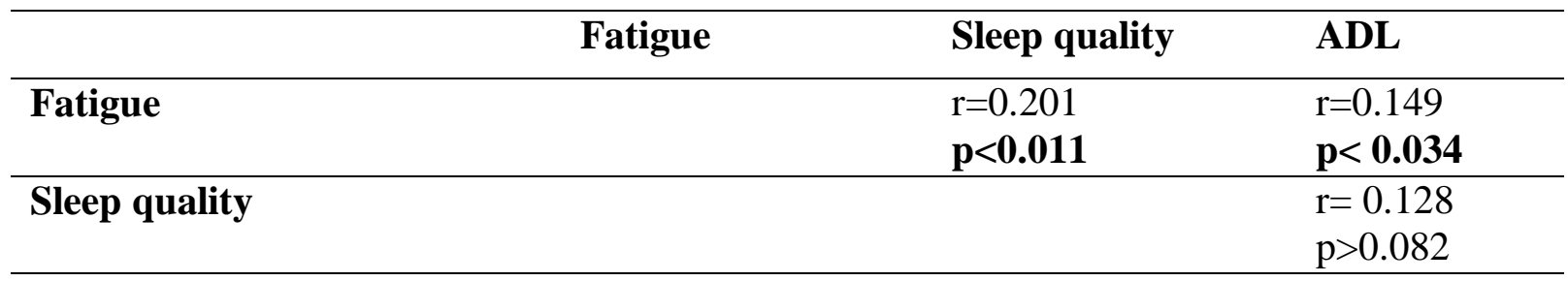

ADL: Katz Activities of Daily Living Scale

Fatigue showed a weak significant association with both sleep quality and activities

Table 3. Determinants of fatigue level of daily living. Determinants of fatigue level were given on Table 3.

\begin{tabular}{|c|c|c|c|c|c|}
\hline & \multicolumn{2}{|c|}{$\begin{array}{c}\text { Unstandardized } \\
\text { Coefficients } \\
\end{array}$} & \multirow[b]{2}{*}{ Beta } & \multirow[b]{2}{*}{$\mathbf{t}$} & \multirow[b]{2}{*}{$\mathbf{p}$} \\
\hline & B & Std. Error & & & \\
\hline Age &, 030 &, 016 & ,236 & 1,880 &, 065 \\
\hline Hemodialysis sessions &,- 014 &, 065 &,- 025 &,- 208 &, 836 \\
\hline Gender & $-1,179$ & ,510 &,- 291 & $-2,310$ &, $\mathbf{0 2 4}$ \\
\hline PSQI &,- 029 &, 054 &,- 068 &,- 536 & ,594 \\
\hline
\end{tabular}

PSQI: Pittsburgh Sleep Quality Index

\section{DISCUSSION AND CONCLUSION}

Hemodialysis patients experience fatigue due to various reasons such as accumulation of metabolic waste in the body, fluid-electrolyte imbalances, abnormal energy expenditure, anemia and depression (Yurtsever and Bedük, 2003; Merlino and Gigli, 2008). Sense of tiredness may persist even after rest (Jhamb et al., 2008; Solak et al., 2011). Fatigue symptom is commonly reported in studies and occurs before and after dialysis. Feelings of exhaustion cause lack of motivation and reduced physical activity in individuals (Aucella et al., 2014; Delgado and Johansen, 2011). Pre- and post-treatment assessments performed in the current study yielded findings that are consistent with the literature. The finding of increased fatigue severity after the treatment is noteworthy.
Sleep disturbances are prevalent among patients with CRF (Liaveri et al., 2017). In researches, it was stated that sleep quality may be adversely affected through several mechanisms including excessive daytime sleepiness and increased inflammatory cytokines in individuals undergoing hemodialysis treatment (Chen et al., 2011; İnal, 2019). In a study which examined sleep quality in patients on hemodialysis treatment, poor sleep quality was reported in $73 \%$ of the participants (Čengić et al., 2012). Similarly, the majority of the patients were found to have poor sleep quality in the current study.

Individualized rehabilitation programs have been demonstrated to be effective in minimizing sleep problems associated with chronic diseases (Kocamaz, and Düger, 2020; Ozberk et al., 2020). Low-intensity aerobic exercises performed 3 times a week for 30-45 minutes were reported to 
improve sleep quality in hemodialysis patients (Yurtkuran, 2007). An important finding of the current study is the high number of patients with poor sleep quality. Further studies are needed to examine both the short- and long- term effectiveness of personalized rehabilitation programs in individuals with chronic renal failure.

Chronic diseases cause functional limitations by substantially disrupting the daily lives of individuals (Yazıc1 and Kalayc1, 2015). In the International Dialysis Outcomes and Practice Patterns Study (DOPPS), the percentage of patients who could perform each activity of daily living without assistance ranged from $47 \%$ (doing housework) to $97 \%$ (eating), generally depending on the age of the individual (Matsuzawa et al., 2014; Jassal et al., 2016; Yoda et al., 2012; Aydin, 2018). The mean age of our patients and their independence in ADLsare in line with those reported in the literature. The Katz Activities of Daily Living questionnaire was used in the current study and all participants were considered independent based on their scores. It is our belief that the absence of a structured tool specific to CRF patients hinders the ability to assess activities of daily living and quality of life in these individuals. Thus, assessment tools that address the changes in activities of daily living in individuals before and after the treatment session and examine their professional and social activities in detail should be developed to fill this gap.

Consistent with literature, fatigue occurred as a common symptom before and after dialysis sessions in patients undergoing hemodialysis treatment for chronic renal failure. Additionally, poor sleep quality and reduced performance in the activities of daily living in the study participants are noteworthy. Hemodialysis causes a number of symptoms that patients have to cope with in their daily lives. In our study, in accordance with the results of the literature, it was observed that the symptoms of fatigue were more common in women before hemodialysis (Bonner et, al. 2010).

Limitations to this study is its crosssectional design and the small number of the sample. The inclusion exclusion criteria of patients were difficult as diabetic neuropathy.

Concluding, we found that CRF patients on hemodialysis have impairment of daily life activity. Decreased fatigue may help to improve increased sleep quality for these patients. It is important to guide patients about individualized rehabilitation programs and maintain their physical activity level during CRF treatment. We believe that future studies on physical therapy and rehabilitation in this area would greatly contribute to the management of chronic renal failure.

\section{Acknowledgement}

We sincerely thank all patients who participated in our study.

Fundings: Authors declare that they have no sponsor in the study design, collection, analysis, interpretation of data, writing of the manuscript, and decision to submit the manuscript for publication.

Conflicts of interest: All authors have no conflicts of interest with respect to the data collected and procedures used within this study.

Ethics Approval: Dated 06.11.2018, No.2018/17 Availability of Data: The data used to support the findings of this study are available from them corresponding author upon request.

\section{REFERENCES}

Ağargün, M.Y., Kara, H., Anlar, Ö. (1996). The Validity and Reliability of The Pittsburgh Sleep Quality Index. Turkish Journal of Psychiatry; 7(2):107-15

Aucella, F., Gesuete, A., \& Battaglia, Y. (2014). A "Nephrological" Approach to Physical Activity. Kidney and Blood Pressure Research, 39(2-3), 189-196.

Aydin, N. S. (2018). Comparison of The Quality of Life, Physical Performance, Physical Activity, Daily Life Activity, Depression Level and Pain Level of Patients on Hemodialysis and Peritoneal Dialysis.

Aydın, Z., Ersoy, İ., Baştürk, A., Kutlucan, A., Göksu, S., Güngör, G., \& Tamer, M. N. (2009). Determinants of Limitation in Activities of Daily Living in Community Dwelling Elderly. Geriatri ve Geriatrik Nöropsikiyatri, 1(2), 9-18.

Bonner, A., Wellard, S., \& Caltabiano, M. (2010). The impact of fatigue on daily activity in people with chronic kidney disease. Journal of clinical nursing, 19(21-22), 3006-3015. 
Čengić, B., Resić, H., Spasovski, G., Avdić, E., \& Alajbegović, A. (2012). Quality of Sleep in Patients Undergoing Hemodialysis. International Urology and Nephrology, 44(2), 557-567.

Chen, H. Y., Cheng, I. C., Pan, Y. J., Chiu, Y. L., Hsu, S. P., Pai, M. F., ... \& Wu, K. D. (2011). Cognitive-Behavioral Therapy for Sleep Disturbance Decreases Inflammatory Cytokines and Oxidative Stress in Hemodialysis Patients. Kidney International, 80(4), 415-422.

Delgado, C., \& Johansen, K. L. (2012). Barriers to Exercise Participation Among Dialysis Patients. Nephrology Dialysis Transplantation, 27(3), 1152-1157.

Fonseca, D., Nisihara, R., Kavilhuka, J., Coan Tenorio, P., \& Skare, T. (2020). Arm and hand function in hemodialysis patients: A cross sectional analytical study. Scientia Medica, 30(1).

Girndt, M. (2017). Diagnosis and Treatment of Chronic Kidney Disease. Internist (Berl) Mar;58(3):243-256. doi: 10.1007/s00108017-0195-2.

İnal, Ö. (2019). İnal, Özgü., The Effect of ClientCentered Occupational Therapy Intervention on Occupational Performance and Quality of Life in Patients Undergoing Hemodialysis. Hacettepe University, Occupational Therapy Program Graduate School Health Sciences, $\mathrm{PhD}$ Thesis, Ankara

Jassal, S. V., Karaboyas, A., Comment, L. A., Bieber, B. A., Morgenstern, H., Sen, A., ... \& Robinson, B. M. (2016). Functional Dependence and Mortality in The International Dialysis Outcomes and Practice Patterns Study (DOPPS). American Journal of Kidney Diseases, 67(2), 283292.

Jhamb, M., Weisbord, S.D., Steel, J.L., Unruh, M. (2008). Fatigue in Patients Receiving Maintenance Dialysis: A Review of Definitions, Measures, and Contributing Factors American Journal of Kidney Diseases Volume 52, Issue 2, August, Pages 353-365.

Kocamaz, D, and Düger T. (2020). Breast Cancer and Exercise. In Breast Cancer Biology. Intech Open.
Lee, K.A., Hicks, G., Murcia, G.N. (1991). Validity and Reliability of a Scale to Assess Fatigue. Psychiatry Research Volume 36, Issue 3, March, Pages 291-298.

Liaveri, P. G., Dikeos, D., Ilias, I., Lygkoni, E. P., Boletis, I. N., Skalioti, C., \& Paparrigopoulos, T. (2017). Quality of Sleep In Renal Transplant Recipients and Patients on Hemodialysis. Journal of Psychosomatic Research, 93, 96-101.

Matsuzawa, R., Matsunaga, A., Wang, G., Yamamoto, S., Kutsuna, T., Ishii, A. (2014). Relationship Between Lower Extremity Muscle Strength and All-Cause Mortality in Japanese Patients Undergoing Dialysis. Phys Ther 94(7):947-56.

Merlino, G., Gigli, G. L., \& Valente, M. (2008). Sleep Disturbances in Dialysis Patients. Journal of Nephrology, 21, S66-70.

Noel, N. and Rieu, K. G. P. (2012). Chronic Kidney Disease: Therapy and Care Rev Prat. Jan, 62(1):43-51.

Ozberk, S., Karadibak, D., Polat, M. (2020). Predictors of Exercise Capacity in Chronic Venous Disease Patients. Phlebology, 35(3), 190-198.

Solak, Y., Atalay, H., Kan, S., Kaynar, M., Bodur, S., Yeksan, M., \& Turk, S. (2011). Effects of Sildenafil and Vardenafil Treatments on Sleep Quality and Depression in Hemodialysis Patients with Erectile Dysfunction. International Journal of Impotence Research, 23(1), 27-31.

Tel, H., Tel, H., Sabancıoğulları, S, (2006). Status of Maintenance of Activities of Daily Living and Experience of Loneliness in Elder Than 60 Years Old Living at Home And in Institutions. Turkish Journal of Geriatrics, 9(1), 34-40.

T1ğl1. A.A. and Yakut, Y. (2020). Effect of Calisthenic Exercise Program on Inflammatory Markers, Quality of Life and Exercise Capacity After Renal Transplantation: A Randomized Controlled Study. J Exerc Ther Rehabil. 7(1):01-10

Tuna, D., Ovayolu, N., Kes, D. (2018). Common Problems in Hemodialysis Patients and the Problem Solving Recommendations. Journal of Nephrology Nursing, 13(1), 17-25.

Yazıcı SÖ, Kalaycı İ. (2015). Evaluation of Activities of Daily Living in Elderly Patients. Suleyman Demirel University Journal of 
Engineering Sciences and Design 3(3), SI:Ergonomi; 385-390,ISSN:1308-6693

Yoda, M., Inaba, M., Okuno, S., Yoda, K., Yamada, S., Imanishi, Y., ... \& Shoji, S. (2012). Poor Muscle Quality as a Predictor of High Mortality Independent of Diabetes in Hemodialysis Patients. Biomedicine \& Pharmacotherapy, 66(4), 266-270.

Yurtkuran, M., Alp, A., \& Dilek, K. (2007). A Modified Yoga-Based Exercise Program in Hemodialysis Patients: A Randomized Controlled Study. Complementary Therapies in Medicine, 15(3), 164-171.

Yurtsever, S., Bedük, T. (2003). Evaluation of Fatigue on Hemodialysis Patients. Journal of Research and Development in Nursing; $2: 3-12$.

How to cite this article: Özberk, S. and Kocamaz, D. (2020). Evaluation of Fatigue, Sleep Quality and Activities of Daily Living in Patients with Chronic Renal Failure. Int J Disabil Sports Health Sci;3(2):140-146. https://doi.org/10.33438/ijdshs. 779038 